\title{
KAJIAN FARMAKOGNOSTIK HERBA MENIRAN HIJAU (Phyllanthus niruri L.) dan HERBA MENIRAN MERAH (Phyllanthus urinaria L.)
}

\author{
Virsa Handayani ${ }^{1)}$, Nurfadillah ${ }^{1)}$ \\ virsaichafarmasi@yahoo.com \\ ${ }^{1)}$ Fakultas Farmasi Universitas Muslim Indonesia Makassar
}

\begin{abstract}
ABSTRAK
Herba meniran secara empiris telah lama digunakan oleh masyarakat sebagai obat tradisional. Ditinjau dari prospek yang sangat potensial sebagai bahan obat maka perlu dilakukan kajian farmakognostik sampel untuk pengendalian mutu dan keaslian simplisia. Penelitian ini bertujuan memberikan dasar ilmiah mengenai gambaran farmakognostik secara kualitatif dan kuantitatif. Hasil penelitian secara kualitatif dan kuantitatif telah dideskripsikan. Kajian morfologi pada daun herba meniran hijau (Phyllanthus niruri L.) dan daun herba meniran merah (Phyllanthus urinaria L.) memiliki bentuk yang sama. Pada batang memiliki perbedaan, meniran hijau percabangannya monopodial dan berwarna hijau sedang meniran merah percabangannya simpodial dan berwarna merah. Pada akar sama-sama berakar tunggang serta berwarna putih kekuningan. Berdasarkan kajian anatomi pada meniran hijau (Phyllanthus niruri L.) dan Meniran merah (Phyllanthus urinaria L.) memiliki bentuk yang sama baik dari daun, batang maupun akarnya. Berdasarkan kajian identifikasi kandungan kimianya pada meniran hijau (Phyllanthus niruri L.) mengandung tanin (katekol), saponin dan karbohidrat, sedangkan pada meniran merah (Phyllanthus urinaria L.) hanya mengandung tanin (katekol) dan saponin.
\end{abstract}

Keyword: Phyllanthus niruri, Phyllanthus urinaria, Farmakognostik

\section{PENDAHULUAN}

\section{Latar Belakang}

Secara geografis negara Indonesia merupakan suatu negara yang memiliki banyak jenis tanaman yang dapat dimanfaatkan sebagai obat tradisional (Miksusanti, et al, 2009) Salah satu tanaman yang memiliki potensi untuk dikembangkan sebagai obat tradisional adalah herba meniran hijau (Phyllanthus niruri L.) dan herba meniran merah (Phyllanthus urinaria L.). Herba meniran merupakan tanaman liar yang dapat tumbuh disegala musim dan merupkan tumbuhan yang memiliki beberapa khasiat, diantaranya kanker, SARS, hepatitis, demam berdarah dan kencing batu (Sulaksana, 2004). Herba meniran mengandung filantin, hipofilantin, damar, kalium, tanin, saponin, flavanoid dan triterpenoid (Heyne, 1987).

Pada penelitian ini akan dilakukan uji farmakognostik dan aspek standarisasinya sehingga diharapkan kelayakan pemanfaatan tumbuhan meniran hijau dan meniran merah yang merupakan kekayaan hayati bangsa
Indonesia dapat ditingkatkan. Adapun tujuan yang ingin dicapai adalah untuk memperoleh data identifikasi utuk membandingkan antara tumbuhan meniran hijau (Phyllathus niruri L.) dan meniran merah (Phyllathus urinaria L.) secara makroskopik, mikroskopik dan kromatografi lapis tipis.

\section{METODOLOGI PENELITIAN}

A. Alat dan Bahan

Alat yang digunakan meliputi alat-alat gelas (pyrex), Lampu UV 254 dan 366 nm, Mikroskop, seperangkat alat maserasi, Seperangkat alat rotavapor $\left(\mathrm{Ika}^{\circledR}\right.$ Werke @ Rvor), timbangan analitik (O’Houss).

Bahan yang digunkan yaitu aquadest, Asam klorida P, Asam sulfat, Besi (III) klorida, Etanol, Etil asetat, Fehling A, Fehling B, Floroglusin P, Iodine $0,1 \mathrm{~N}$, Kalium hidroksida, Kloralhidrat, Kloroform,bauchardat, dragendorff, lempeng $\mathrm{KLT} \mathrm{GF}_{254}$ (E.Merck), Metanol, n-butanol, nheksan, Tumbuhan meniran hijau 
(Phyllanthus niruri L.) dan meniran merah (Phyllanthus urinaria L.).

\section{a. Pemeriksaan Makroskopik}

Bagian tanaman yang utuh yaitu akar, batang dan daun meniran hijau (Phyllanthus niruri L.) dan meniran merah (Phyllanthus urinaria L.) diambil untuk pemeriksaan morfologi, wujud tanaman dideskripsikan secara umum, termasuk cirri khasnya kemudian data yang diperoleh didokumentasikan (Ditjen POM, 1994).

\section{b. Pemeriksaan Mikroskopik}

Dilakukan pemeriksaan mikroskopik dengan mengamati bentuk sel dan jaringan tumbuhan pada bagian penampang melintang dan membujur dari akar, batang dan daun meniran hijau (Phyllanthus niruri L.) dan meniran merah (Phyllanthus urinaria L.), kemudian bentuk sel - selnya diamati menggunakan mikroskop dan didokumentasikan (Ditjen POM, 1979 ; Fahn, 1991).

\section{c. Pemeriksaan Organoleptik}

Bagian tumbuhan yang utuh (akar, batang dan daun) diamati warna, rasa dan bau selanjutnya didokumentasikan.

\section{d. Reaksi identifikasi kimia}

Identifikasi meliputi golongan lignin, tanin, dioksiantrakinon, fenol, alkaloid, flavanoid, saponin, pati dan aleuron, karbohidrat dengan menggunakan pereaksi spesifik (Gritter, 1991).

\section{e. Ekstraksi Sampel}

1. Ekstraksi secara maserasi dengan pelarut etanol

Ekstraksi dengan metode maserasi dengan pelarut methanol selama 3x 24 jam, hasil ekstraksi diuapkan hingga diperoleh ekstrak kental (Ditjen POM, 1986).

\section{f. Kromatografi Lapis Tipis}

Ekstrak etanol yang diperoleh kemudian dilakukan pemeriksaan secara kromatografi lapis tipis diamati pada UV $254 \mathrm{~nm}, 366 \mathrm{~nm}$ dan disemprotkan dengan $\mathrm{H}_{2} \mathrm{SO}_{4} 10 \%$ serta dihitung nilai Rf (Rohman, 2007 ; Harbone, 1987).
III. HASIL DAN PEMBAHASAN

A. Hasil penelitian

1. Pemeriksaan Makroskopik Tumbuhan Meniran Hijau dan Meniran Merah

Tumbuhan meniran hijau

(Phyllanthus niruri L.) dan meniran merah (Phyllanthus urinaria L.) sama-sama merupakan tumbuhan terna semusim, tumbuh tegak dan tumbuh liar (Sastroamijoyo,1997). Terdapat perbedaan pada tumbuhan meniran hijau dan meniran merah, data dapat dilihat pada tabel 1 .

\section{Pemeriksaan Mikroskopik Tumbuhan Meniran Hijau dan Meniran Merah \\ Dari pemeriksaan makroskopik} tumbuhan meniranan hijau dan meniran merah anatomi daun, susunan jaringan pada penampang melintang terdapat kutikula, epidermis atas, jaringan tiang, xylem, floem, epidermis bawah, jaringan bunga karang dan stomata. Sedangkan susunan jaringan pada penampang membujur terdapat stomata tipe anisositik, sel tetannga, sel penutup. Pada anatomi batang, susunan jaringan pada penampang melintang terdapat epidermis, korteks, endodermis, xylem, kambium, dan floem. Sedangkan susunan jaringan pada penampang membujur terdapat epidermis, korteks, floem, kambium, xylem dan caoksalat. Pada anatomi akar, susunan jaringan pada penampang melintang terdapat epidermis, endodermis, bulu akar, korteks, kambium, xylem, floem. Sedangkan susunan jaringan pada penampang membujur terdapat epidermis, floem, xylem, korteks dan bulu akar.

\section{Pemeriksaan Organoleptik Tumbuhan Meniran Hijau dan Meniran Merah \\ Pengamatan organoleptik}

tumbuhan, dimaksudkan untuk mengetahui sifat-sifat fisik yang khas dari tumbuhan tersebut dengan melakukan pengamatan terhadap kekhususan bentuk, warna, bau dan rasa dari suatu simplisia. Dari hasil pengamatan yang diperolehi, tumbuhan meniran hijau dan meniran merah, pada daun berasa pahit, bau khas dan berwarna hijau. Pada akarnya sama yaitu tidak berasa, bau khas dan berwarna putih kekuningan. Pada batangnya sama-sama berasa pahit dan bau 
khas, namun pada meniran hijau batangnya berwarna hijau sedangkan pada meniran merah batangnya berwarna merah

\section{Reaksi identifikasi kimia}

Dari hasil penelitian menunjukkan bahwa, senyawa yang terdapat dalam serbuk daun meniran hijau (Phyllanthus niruri L.) positif mengandung tanin (katekol), saponin dan karbohidrat pada penambahan pereaksi fehling A dan B. Sedangkan pada meniran merah (Phyllanthus urinaria L.) hanya positif mengandung tanin (katekol) dan saponin. (Dapat dilihat pada tabel 2).

\section{Kromatografi Lapis Tipis}

Pada ekstrak etanol dan n-hexan untuk identifikasi komponen kimianya digunakan cairan pengelusi n-hexan : etil asetat dengan perbandingan $8: 2$ pada penampak sinar UV $254 \mathrm{~nm}$, sinar UV 366 nm dan $\mathrm{H}_{2} \mathrm{SO}_{4} 10 \%$. Data kromatografi lapis tipis dapat dilihat pada tabel 3 dan gambar 1.

Tabel 1. Pemeriksaan Makroskopik

\begin{tabular}{|c|c|c|c|}
\hline No & Pemeriksaan & $\begin{array}{l}\text { Pengamatan } \\
\text { Meniran hijau }\end{array}$ & $\begin{array}{c}\text { Pengamatan } \\
\text { Meniran merah }\end{array}$ \\
\hline 1. & Tumbuhan & $\begin{array}{l}\text { Terna semusim, tumbuh } \\
\text { tegak, tinggi } 38 \mathrm{~cm} \text {, tidak } \\
\text { berbulu, tangkainya } \\
\text { berwarna hijau, tumbuh liar } \\
\text { di tempat-tempat yang } \\
\text { lembab, di sepanjang jalan } \\
\text { dan di antara rerumputan } \\
\text { dalam jumlah yang banyak. }\end{array}$ & $\begin{array}{l}\text { Terna semusim, tumbuh } \\
\text { tegak, tinggi } 20,7 \mathrm{~cm} \text {, tidak } \\
\text { berbulu, pada pangkalnya } \\
\text { agak berkayu, tangkainya } \\
\text { berwarna merah, tumbuh liar } \\
\text { di tempat-tempat yang } \\
\text { lembab, di sepanjang jalan } \\
\text { dan di antara rerumputan } \\
\text { dalam jumlah yang banyak }\end{array}$ \\
\hline 2. & $\begin{array}{l}\text { Daun } \\
\qquad(\text { Folium })\end{array}$ & $\begin{array}{l}\text { Tunggal, berbentuk jorong } \\
\text { (ovalis), ujung (apex) tumpul } \\
\text { (obtusus), pangkal (basis) } \\
\text { membulat (rotundatus), } \\
\text { susunan tulangnya bertulang } \\
\text { menyirip (penninervis), tepi } \\
\text { (margo) rata (integer), } \\
\text { permukaan daun licin } \\
\text { (laevis), panjang } 9 \mathrm{~mm} \text { dan } \\
\text { lebar } 4 \mathrm{~mm} \text {, berwarna hijau } \\
\text { muda. }\end{array}$ & $\begin{array}{l}\text { Tunggal, berbentuk jorong } \\
\text { (ovalis), ujung (apex) tumpul } \\
\text { (obtusus), pangkal (basis) } \\
\text { membulat (rotundatus), tepi } \\
\text { (margo) rata, permukaan } \\
\text { daun licin (laevis), panjang } 9 \\
\text { mm dan lebar } 3 \mathrm{~mm} \text {, } \\
\text { berwarna hijau muda. }\end{array}$ \\
\hline 3. & $\begin{array}{l}\text { Batang } \\
\text { (Caulis) }\end{array}$ & $\begin{array}{l}\text { Basah, berbentuk bulat } \\
\text { (teres), permukaan batang } \\
\text { licin (laevis), arah tumbuh } \\
\text { batang tegak lurus (erectus), } \\
\text { cara percabangan } \\
\text { monopodial, berwarna hijau } \\
\text { muda, tinggi } 24 \mathrm{~cm} \text {. }\end{array}$ & $\begin{array}{l}\text { Basah, berbentuk bulat } \\
\text { (teres), permukaan batang } \\
\text { licin (laevis), arah tumbuh } \\
\text { batang tegak lurus (erectus), } \\
\text { cara percabangan simpodial, } \\
\text { berwarna merah, tinggi } 7,2 \\
\text { cm. }\end{array}$ \\
\hline 4. & $\begin{array}{c}\text { Akar } \\
\text { (Radix) }\end{array}$ & $\begin{array}{l}\text { Termasuk sistem perakaran } \\
\text { tunggang, } \\
\text { berwarna putih kekuningan. }\end{array}$ & $\begin{array}{l}\text { Termasuk sistem perakaran } \\
\text { tunggang, } \\
\text { berwarna putih kekuningan. }\end{array}$ \\
\hline
\end{tabular}


Tabel 2. Reaksi identifikasi kimia

\begin{tabular}{|c|c|c|c|c|c|c|c|}
\hline \multirow{3}{*}{ No } & \multirow{3}{*}{ Uji } & \multirow{3}{*}{ Pereaksi } & \multicolumn{3}{|c|}{ Warna } & \multicolumn{2}{|c|}{ Keterangan } \\
\hline & & & \multirow[t]{2}{*}{ Pustaka } & \multicolumn{2}{|c|}{ Hasil } & & \\
\hline & & & & Mh & Mm & Mh & Mm \\
\hline \multirow[t]{4}{*}{1} & Tanin & $\begin{array}{c}\mathrm{FeCL}_{3} \\
1 \mathrm{~N}\end{array}$ & Hijau & Hijau & Hijau & + & + \\
\hline & \multirow{3}{*}{ b. Pirogalotanin } & Brom & $\begin{array}{l}\text { Terjadi } \\
\text { endapan }\end{array}$ & & & & \\
\hline & & $\begin{array}{c}\mathrm{FeCL}_{3} \\
1 \mathrm{~N}\end{array}$ & Biru & - & - & - & - \\
\hline & & Brom & $\begin{array}{c}\text { Tidak } \\
\text { terbentuk } \\
\text { endapan }\end{array}$ & & & & \\
\hline \multirow[t]{2}{*}{2} & \multirow[t]{2}{*}{ Karbohidrat } & $\begin{array}{c}\text { Luff } \\
\text { Fehling }\end{array}$ & $\begin{array}{c}\text { Endapan } \\
\text { merah }\end{array}$ & $\begin{array}{c}\text { Endapan } \\
\text { hijau }\end{array}$ & $\begin{array}{c}\text { Endapan } \\
\text { hijau }\end{array}$ & $\begin{array}{l}- \\
+\end{array}$ & - \\
\hline & & $\mathrm{A}$ dan $\mathrm{B}$ & $\begin{array}{c}\text { Endapan } \\
\text { kuning- } \\
\text { jingga }\end{array}$ & $\begin{array}{c}\text { Endapan } \\
\text { jingga }\end{array}$ & $\begin{array}{c}\text { Endapan } \\
\text { hijau }\end{array}$ & & \\
\hline 3 & Saponin & HCL 2N & $\begin{array}{c}\text { Terbentuk } \\
\text { buih }\end{array}$ & $\begin{array}{c}\text { Terbentuk } \\
\text { buih }\end{array}$ & $\begin{array}{l}\text { Terbentuk } \\
\text { buih }\end{array}$ & + & + \\
\hline
\end{tabular}

Tabel 3.Hasil kromatografi lapis tipis ekstrak etanol daun meniran hijau (Phyllathus niruri L.) dan meniran merah (Phyllanthus urinaria L.)

\begin{tabular}{|c|c|c|c|c|c|c|}
\hline \multirow{3}{*}{ Ekstrak } & \multicolumn{2}{|c|}{ Sinar UV 254 nm } & \multicolumn{2}{|c|}{ Sinar UV 366 nm } & \multicolumn{2}{c|}{ H2SO4 10\% } \\
\cline { 2 - 8 } & $\begin{array}{c}\text { Nilai } \\
\text { Rf }\end{array}$ & $\begin{array}{c}\text { Warna } \\
\text { noda }\end{array}$ & $\begin{array}{c}\text { Nilai } \\
\text { Rf }\end{array}$ & Warna noda & $\begin{array}{c}\text { Nilai } \\
\text { Rf }\end{array}$ & $\begin{array}{c}\text { Warna } \\
\text { noda }\end{array}$ \\
\hline \multirow{5}{*}{ H1 } & 0,67 & Hijau & 0,67 & Merah muda & 0,85 & Ungu \\
\cline { 2 - 8 } & 0,62 & Kuning & 0,62 & Merah muda & 0,67 & Hijau \\
\cline { 2 - 8 } & 0,47 & Kuning & 0,47 & Merah muda & 0,62 & Kuning \\
\cline { 2 - 8 } & 0,36 & Kuning & 0,36 & Merah muda & 0,47 & Kuning \\
\cline { 2 - 8 } & 0,27 & Hijau & 0,27 & Merah muda & 0,36 & Kuning \\
\hline & 0,20 & Kuning & 0,20 & Merah muda & 0,27 & Hijau \\
\hline \multirow{5}{*}{ M1 } & - & - & - & - & 0,20 & Kuning \\
\hline & 0,67 & Hijau & 0,67 & Merah muda & 0,85 & Ungu \\
\cline { 2 - 8 } & 0,62 & Kuning & 0,62 & Merah muda & 0,67 & Hijau \\
\cline { 2 - 8 } & 0,47 & Kuning & 0,47 & Merah muda & 0,62 & Kuning \\
\cline { 2 - 8 } & 0,36 & Kuning & 0,36 & Merah muda & 0,47 & Kuning \\
\cline { 2 - 8 } & 0,27 & Hijau & 0,27 & Merah muda & 0,36 & Kuning \\
\cline { 2 - 7 } & 0,20 & Kuning & 0,20 & Merah muda & 0,27 & Hijau \\
\cline { 2 - 7 } & - & - & - & - & 0,20 & Kuning \\
\hline
\end{tabular}

Keterangan :

H1 = Ekstrak etanol daun meniran hijau (Phyllanthus niruri L.)

M1 = Ekstrak etanol daun meniran merah (Phyllanthus urinaria L.) 


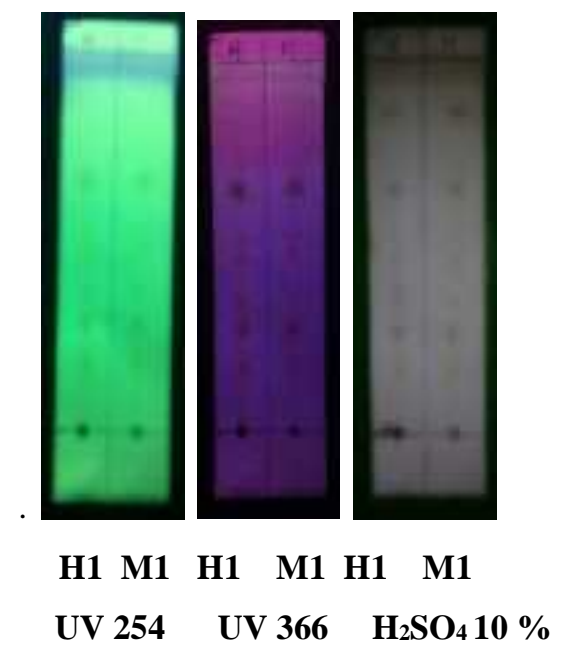

Keterangan:

\section{UV 254 UV $366 \quad \mathrm{H}_{2} \mathrm{SO}_{4} 10 \%$}

H1 = Ekstrak etanol daun meniran hijau (Phyllanthus niruri L.)

M1 = Ekstrak etanol daun meniran merah (Phyllanthus urinaria L.)

Fase gerak $\quad$ : n-hexan : etil asetat $(8: 2)$

\section{KESIMPULAN}

1. Pemeriksaan makroskopik (morfologi) tumbuhan meniran hijau (Phyllanthus niruri L.) dan meniran merah (Phyllanthus urinaria L.) Perbedaannya terletak pada tinggi tumbuhan, pangkal, ukuran daun, percabangan dan warna pada batang.

2. Pemeriksaan mikroskopik (anatomi) diperoleh hasil yang sama baik pada bentuk daun, batang dan akar dari meniran hijau (Phyllanthus niruri L.) dan meniran merah (Phyllanthus urinaria L.)

3. Identifikasi komponen kimia serbuk daun pada meniran hijau (Phyllanthus niruri L.) positif mengandung tanin (katekol), saponin dan karbohidrat. Sedangkan pada meniran merah (Phyllanthus urinaria L.) hanya positif mengandung tanin (katekol) dan saponin.

4. Profil kromatografi lapis tipis, lebih banyak noda yang tampak pada senyawa non polar (n-hexan) dengan eluen nhexan : etil asetat (8: 2) dengan penampak noda sinar UV $254 \mathrm{~nm}$, sinar UV $366 \mathrm{~nm}$ dan $\mathrm{H}_{2} \mathrm{SO}_{4} \quad 10 \%$ pada meniran hijau (Phyllanthus niruri L.).

\section{DAFTAR PUSTAKA}

1. Direktorat Jendral Pengawasan Obat dan Makanan.1987. Analisis Obat Tradisional, Jilid I. Departemen Kesehatan RI, Jakarta.
2. Direktorat Jenderal Pengawasan Obat dan Makanan, 1979. Farmakope Indonesia, Edisi III. Departemen Kesehatan Republik Indonesia, Jakarta.

3. Direktorat Jendral Pengawasan Obat dan Makanan, 1995. Farmakope Indonesia, Edisi IV. Departemen Kesehatan Republik Indonesia, Jakarta.

4. Direktorat JendraI Pengawasan Obat dan Makanan. 2000. Parameter Standar Umum Ekstark Tumbuhan Obat. Departemen Kesehatan RI, Jakarta.

5. Direktorat Jenderal Pengawasan Obat dan Makanan, 1986. Sediaan Galenik. Departemen Kesehatan Republik Indonesia, Jakarta.

6. Fahn, A. 1991. Anatomi Tumbuhan. Edisi III. Gadjah mada University Press, Yogyakarta.

7. Gritter, RJ., Bobbit, JM., Schwarting AE., 1991. Pengantar Kromatografi. Penerjemah : Padmawinata. Penerbit ITB, Bandung.

8. Harborne, J. B., 1987, Metode Fitokimia, Penuntun Cara Modern Mengekstraksi Tumbuhan, Penerjemah: Padmawinata, Edisi kedua, ITB, Bandung. 
9. Heyne, K. 1987. Tumbuhan Berguna Indonesia. Jilid III. Badan Litbang Kehutanan. Departemen Kehutanan. Jakarta.

10. Miksusanti., Betty sri laksmi,J.,Rizal syarief, Bambang pontjo, Gatot tri mulyadi., (2009), Antibacterial Activity Of Temu Kunci Tuber (Kaempheria pandurata) Essential Oil Against Bacillus cereus, Medical Journal of Indonesia, vol 18 No 1, p. 11.

11. Rohman, A., 2007. Metode Kromatografi Untuk Analisis Makanan. Penerbit Pustaka Pelajar. Yogyakarta.

12. Roth,H.J, Biaschek. 1988. Analisis Farmasi. Penerjemah Sarjono Kisman. Universitas Gadjah Mada Press, Yogyakarta.

13. Sastroamidjojo, S. 1997. Obat Asli Indonesia, Penerbit Dian Rakyat Jakarta.

14. Steenis, V.2006. Flora. Penerjemah: Moes Surjowinoto, PT. Pradnya Paramita. Jakarta.

15. Sulaksana. J. 2004. Meniran, Budi Daya dan Pemanfaatan untuk Obat. Jakarta. 